Instructions for authors, subscriptions and further details:

http://mcs.hipatiapress.com

\title{
Men, Masculinities and Teaching in Early Childhood Education
}

Javier Díez-Palomar ${ }^{1}$

1) University of Barcelona

Date of publication: October $21^{\text {th }}, 2016$

Edition period: October 2016-February 2017

To cite this article: Diez-Palomar, J. (2016). Men, Masculinities and

Teaching in Early Childhood Education [Review of the book]. Masculinities and Social Change, 5(3), 321-322. doi: 10.17583/MCS.2016.2351

To link this article: http://dx.doi.org/10.4471/MCS.2016.2351

PLEASE SCROLL DOWN FOR ARTICLE

The terms and conditions of use are related to the Open Journal System and to Creative Commons Attribution License (CC-BY). 
MCS - Masculinities and Social Change Vol. 5 No. 3 October 2016

pp. 321-322

\section{Reviews (I)}

Simon Brownhill, Jo Warin and Inga Wernersoon (eds.) (2016), Men, Masculinities and Teaching in Early Childhood Education. London: Routledge. ISBN: 978-1-138-79771-0

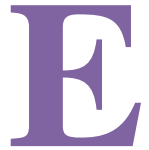

ste libro editado por Simon Brownhill, Jo Warin and Inga Wernersoon discute el papel que juegan los hombres en la educación infantil, no solo desde un punto de vista professional, como cuidadores, sino que también desde el ámbito de los valores, las actitudes, las creencias o el imaginario social que envuelve la educación infantil.

El mundo de la educación siempre ha estado influenciado por los temas de género. En la enseñanza de las matemáticas, por ejemplo, durante varias décadas se ha tratado de "recuperar" a los "chicos rebeldes"; este perfil de estudiante que para ser "popular" en el grupo de iguales tenía que alardear de sacar malos resultados académicos. Los roles de género se han utilizado muchas veces como referentes para la definición de la identidad en ese tipo de situaciones, asociando el rol violento a un determinado tipo de chicos.

Este libro es una alternativa que discute en profundidad, y desde la educación infantil, este rol de género; y en concreto, de "ser hombre." Los autores comienzan haciendo una reflexión, y es que "no quieren escribir un libro para recuperar a los chicos rebeldes", sino que lo que plantean a lo largo de estas páginas, junto con todas las personas que escriben los diferentes capítulos, es plantear que existen otros tipos de masculinidad, más allá de la masculinidad hegemónica.

Junto a esta reflexión de fondo, el libro presenta tres partes bien diferenciadas. En la primera de ellas el tema central es la discusión de la masculinidad desde las esferas política y legislativa. A través de varios capítulos, los autores invitados en este volumen ponen ejemplos de diversos

2016 Hipatia Press

ISSN: 2014-3605

DOI: 10.17583/MCS.2016.2351 
países, sobre cómo se regula el papel y el rol del "hombre" en la educación infantil. Aspectos como la interpretación reproductora de los roles de género que los niños y las niñas ya en la escuela infantil aprenden cuando ven a su alrededor cómo actúan sus "mayores", el cómo el profesorado (los cuidadores y las cuidadoras) construyen una imagen de la profesión de careworker que es eminentemente feminizada, a pesar de que también hay hombres que cuidan a niños/as de manera profesional, etc., son temas todos ellos con un alto contenido crítico, y los autores/as nos invitan con sus reflexiones a pensar de manera crítica cómo definimos la identidad de género en nuestras escuelas.

En la segunda parte el tema estrella son los estudios de caso sobre género, aprendizaje y care. En lugares tan diferentes como Indonesia o Noruega, las autoras de los capítulos de esta parte del libro relatan emocionantes ejemplos que ilustran el debate sobre ideologías, creencias, actitudes, y cómo todo ello crea una determinada identidad de género que se traspasa a nuestros hijos y nuestras hijas en las escuelas maternales y de infantil.

En la tercera parte, las autoras invitadas regresan al enfoque profesionalizador del trabajador/a cuidador/a de niños/as. En Suecia, por ejemplo, se relata cómo los chicos que trabajan en las escuelas de infantil son "pioneros", puesto que se adentran en un terreno profesional tradicionalmente reservado a las mujeres. En Japón, a su vez, vemos que el ser "maestro de educación infantil" está rodeado de toda una serie de normas que definen y ponen los límites del quehacer profesional del hombre, desde el punto de vista de su rol e identidad de género.

En definitiva, se trata de un libro innovador, que abre nuevas fronteras y, en buena mesura, inspirador, para repensar de manera crítica el papel del hombre como maestro de escuela maternal y de infantil. ¿Tienen los hombres que feminizarse o podemos ser capaces de construir una identidad masculina alternativa, que no se deje avasallar, pero a la vez, profundamente respetuosa con los valores humanos, de género, comprometida con el rechazo total a la violencia, y profundamente masculina? Dejo ahí la pregunta para animar a los futuros lectores y lectoras en sus discusiones.

Javier Díez-Palomar, University of Barcelona jdiezpalomar@ub.edu 